\title{
EVALUATION OF NEUTROPHIL-LYMPHOCYTE RATIO AND ARTERIAL STIFFNESS INDICES AMONG YOUNG PREHYPERTENSIVES: A CROSS-SECTIONAL STUDY
}

\begin{abstract}
DEEPIKA $\mathbf{V}^{1,2}$, VIJAYA KUMAR $\mathrm{R}^{3 *}$
${ }^{1}$ Department of Bharath University, Selaiyur, Chennai, Tamil Nadu - 600 073, India. ${ }^{2}$ Department of Physiology, Sri Manakula Vinayagar Medical College and Hospital, Puducherry - 605 107, India. ${ }^{3}$ Department of Physiology, Sri Lakshmi Narayana Institute of Medical Sciences, Puducherry, India. Email: deepy843@gmail.com
\end{abstract}

Received: 21 August 2017, Revised and Accepted: 06 October 2017

ABSTRACT

Objective: The aim of the present study is to evaluate the arterial stiffness indices and neutrophil-lymphocyte ratio (NLR) in young prehypertensives.

Methods: This was a cross-sectional study carried as a part of the medical health check-up program conducted on 150 students joining $1^{\text {st }}$ year MBBS. Based on their blood pressure (BP) recordings they were classified as normotensives and prehypertensives. Arterial stiffness indices were assessed using finger photoplethysmography, and NLR was evaluated using automated hematological analyzer. Student's t-test and Pearson's correlation were performed using SPSS version 16 and $\mathrm{p}<0.05$ was considered as statistically significant.

Results: Of the 150 subjects, 106 were recruited for the present study. Based on BP, they were grouped as normotensives (n=66) and prehypertensives $(n=40)$. Arterial stiffness indices, namely, stiffness index (SI) and reflection index (RI) reported a significant increase among the prehypertensive group with $\mathrm{p}=0.003$ and $\mathrm{p}=0.002$, respectively. SI and RI showed a positive correlation with systolic BP, diastolic BP, heart rate, and body mass index (BMI). NLR reported a significant increase in a prehypertensive group with $\mathrm{p}=0.03$ but no correlation was found between NLR and arterial stiffness indices.

Conclusion: Targeting the high-risk individuals, based on increased arterial stiffness, NLR, BMI and BP, for earlier lifestyle modifications could act as a potential preventive strategy to inhibit the development of cardiovascular diseases.

Keywords: Prehypertension, Stiffness index, Reflection index, Neutrophil-lymphocyte ratio.

(C) 2018 The Authors. Published by Innovare Academic Sciences Pvt Ltd. This is an open access article under the CC BY license (http://creativecommons. org/licenses/by/4. 0/) DOI: http://dx.doi.org/10.22159/ajpcr.2018.v11i1.22150

\section{INTRODUCTION}

High blood pressure (BP) is ranked as the third most important risk factor attributable burden of disease in South Asia [1]. As per the study conducted in 2005 by Global burden of hypertension, the percentage of hypertension rates are projected to increase from $20.6 \%$ to $22.9 \%$ in men and $20.9 \%$ to $23.6 \%$ in women in 2025 [2]. In our society, mild increase in BP values does not gain much attention, as the subject is asymptomatic and is apparently healthy. Therefore, in 2003, the seventh report of Joint National Committee for prevention, detection, evaluation and treatment of high BP (JNC 7) introduced the term "prehypertension," that is, systolic BP (SBP) of 120-139 mmHg and/or diastolic BP (DBP) of $80-89 \mathrm{mmHg}$ [3]. It is indicated that prehypertensives are at greater risk of developing cardiovascular diseases (CVDs), so targeting the younger age group could be of a potential boon to the individual and society, to create awareness for early lifestyle modifications.

Hypertension is associated with arterial stiffness [4]. Increased arterial stiffness in normotensive individuals is associated with accelerated BP progression and increased risk for incident hypertension during followup $[5,6]$ but literature review indicates meager and nonconclusive results on the association between prehypertension and arterial wall stiffness.

Arterial stiffness measured using digital volume pulse (DVP) analysis has been proved to be validated and reproducible technique with minimal intraobserver variation [7] and is a more sensitive tool in risk stratification for CVD in comparison to plasma glucose, total cholesterol, and waist to hip ratio in apparently healthy population [8].

Arterial stiffness and hypertension are documented to stimulate both innate and adaptive immunity. Activated neutrophils represent nonspecific systemic inflammation, and lymphocytes are a marker of the immune system physiological stress response. Neutrophillymphocyte ratio (NLR) integrates these two important and opposite immune pathways, and thus serves as a measure of both systemic inflammation and stress response [9]. Furthermore, NLR is recognized as an independent critical risk factor of CVDs [10]. NLR is reported to be associated with BP variability [11] and its predictive value in peripheral arterial disease and its prognostication of the presence, severity, and extent of coronary artery disease has already been demonstrated [12].

Reports targeting younger individuals with prehypertension and correlating BP variables with arterial stiffness indices and NLR ratio are lacking in Indian scenario. With this perspective in mind, the current study aimed to evaluate the association between arterial stiffness indices and NLR in young prehypertensives.

\section{METHODS}

This was a cross-sectional study conducted in the Department of Physiology, Sri Manakula Vinayagar Medical College and Hospital, Pondicherry 2015-2016. All 150 students of age 18-25 joining $1^{\text {st }}$ year MBBS who underwent the medical health check-up program were recruited for the study. The study was commenced after obtaining approval from the Human Ethical Committee and written informed consent was obtained from all subjects. A review of medical history and physical examination were performed. All baseline characteristics and related anthropometrics including age, height, weight, and body mass index (BMI) were acquired from the study participants.

\section{BP measurements}

$\mathrm{BP}$ was measured in the right arm in the sitting position using a standard mercury sphygmomanometer after a 10-min rest period. 
Three measurements were taken at 5 min interval, and the mean of three measurements was considered for analysis. Based on the BP measurements, the study participants were divided into two groups as normotensives and prehypertensives [3]. Group I - Normotensives: SBP $<120 \mathrm{mmHg}$ and DBP $<80 \mathrm{mmHg}$. Group II - Prehypertensives (SBP: $120-139 \mathrm{mmHg}$ and/or DBP 80-89 $\mathrm{mmHg}$ ).

\section{Inclusion criteria}

Healthy subjects of age group 18-25 years with no medical illness and SBP between $<120$ and $139 \mathrm{mmHg}$ and DBP between $<80$ and $89 \mathrm{mmHg}$ were include from the study.

\section{Exclusion criteria}

Subjects with SBP $>140 \mathrm{mmHg}$ and DBP $>90 \mathrm{mmHg}$ and subjects with ongoing medical illness or any drug treatment were excluded from the study.

\section{Finger plethysmography}

DVP was measured using devise RMS polyrite vital module LF201308, using infrared light with wavelength of $940 \mathrm{~nm}$; placed on the right index finger of the subject. The main principle of this device is conversion of pressure changes to voltage changes by means of the pressure transducer. DVP was analyzed by software virtual oscilloscope. DVP contains two peaks: Systolic peak and diastolic peak. The former peak was due to pulse wave transmitted from the left ventricle to the finger directly, and the diastolic peak arose from pulse wave transmitted along the aorta to the small arteries in the lower part of the body, from where they were again reflected along the aorta as a reflected wave. This path length was directly proportional to the subject's height $(\mathrm{h})$. Pulse transit time $(\Delta \mathrm{T})$ was measured as the time duration between systolic peak and diastolic peak. The magnitudes of systolic and diastolic peak were also measured. Stiffness index (SI) and reflective index (RI) were calculated automatically using the following formulas:

\section{SI=Subject's height $(\mathrm{h}) /$ Pulse transit time $(\Delta \mathrm{T})$.}

$\mathrm{RI}=$ Magnitude of diastolic peak $\times 100 /$ Magnitude of systolic peak.

\section{Hematological parameters}

About $3 \mathrm{ml}$ of peripheral venous blood was withdrawn during the health check-up program and hematologic indices were calculated from complete blood count using automated hematological analyzer. NLR was calculated by dividing the neutrophil count by the lymphocyte count.

\section{Data analysis}

Data entry and statistical analysis were performed using the Microsoft Excel and SPSS 16, respectively. The means and standard deviations were calculated. Student'st-test was used to assess differences between means. $\mathrm{p}<0.05$ was taken for statistical significance. The relationship between various parameters was assessed by Pearson correlation analysis.

\section{RESULTS}

Out of 150 students screened, 27 students did not satisfy the inclusion criteria and 17 subjects were not willing to participate. A total of 106 subjects were selected for the study, of these 66 were normotensives ( 35 males and 31 females), and 40 were prehypertensives (23 males and 17 females). Fig. 1 represents the subject recruitment and categorization.

Table 1 summarizes comparison of basal anthropometric measurements between the two groups. There was no significant difference in age among the two groups $(\mathrm{p}=0.87)$. Height $\left(\mathrm{p}=0.02^{*}\right)$, weight $\left(\mathrm{p}=0.0001^{* *}\right)$, waist circumference (WC) $\left(\mathrm{p}=0.0001^{* *}\right)$, hip circumference (HC) ( $\left.\mathrm{p}=0.0001^{* *}\right)$, and BMI ( $\left.\mathrm{p}=0.0001^{* *}\right)$ were found to be significantly increased among the prehypertensive group.

Table 2 summarizes increased basal cardiovascular parameters among the prehypertensives with $\mathrm{p}=0.0001^{* *}$ as compared to normotensives.
Table 3 summarizes the significant increase in stiffness index (SI) $\left(\mathrm{p}=0.003^{* *}\right)$ and reflection index (RI) $\left(\mathrm{p}=0.002^{* *}\right)$ among the prehypertensive group compared to the normotensive group.

Table 4 summarizes significant increase in hemoglobin $\left(\mathrm{p}=0.0001^{* *}\right)$, hematocrit $\left(\mathrm{p}=0.0001^{* *}\right)$, erythrocyte sedimentation rate $\left(\mathrm{p}=0.0001^{* *}\right)$, total leukocyte count $\left(\mathrm{p}=0.04^{*}\right)$, neutrophil $\left(\mathrm{p}=0.009^{* *}\right)$, monocyte $\left(\mathrm{p}=0.02^{*}\right)$, lymphocyte $\left(\mathrm{p}=0.01^{*}\right)$, and NLR $\left(\mathrm{p}=0.03^{*}\right)$.

Table 5 summarizes the correlation between SI and RI with BMI, BP, HR, and NLR. Except NLR all other parameters proved to be significantly correlated with arterial stiffness indices.

\section{DISCUSSION}

In our present study, the overall prevalence of prehypertension was reported as $37.73 \%$ and males were predominantly prehypertensives with a prevalence rate of $57.5 \%$. Similar reports are found in another study where the prevalence rate of prehypertension and risk of CVD was greater among men compared to women [13]. The lower levels of BP may be probably due to the protective effects of estrogen on the cardiovascular system [14].

BMI, WC, and HC among the prehypertensive group were found to be significantly increased compared to the normotensive group. A study among Indian population reported that prehypertensive and hypertensive individuals had higher BMI, central obesity and sedentary lifestyle [15]. BMI is most commonly used surrogate measure of

Table 1: Basal anthropometric parameters in two groups

\begin{tabular}{llll}
\hline Parameters & $\begin{array}{l}\text { Normotensives } \\
(\mathbf{n = 6 6 )}\end{array}$ & $\begin{array}{l}\text { Prehypertensives } \\
(\mathbf{n = 4 0 )}\end{array}$ & p value \\
\hline Age (years) & $18.68 \pm 0.99$ & $18.65 \pm 0.95$ & 0.87 \\
Height (m) & $1.61 \pm 0.09$ & $1.66 \pm 0.1$ & $0.02^{*}$ \\
Weight $(\mathrm{kg})$ & $58.53 \pm 11.63$ & $76.91 \pm 21.44$ & $0.0001^{* *}$ \\
WC $(\mathrm{cm})$ & $81.94 \pm 9.65$ & $93.23 \pm 16.04$ & $0.0001^{* *}$ \\
HC $(\mathrm{cm})$ & $93.26 \pm 8.71$ & $105.22 \pm 15.36$ & $0.0001^{* *}$ \\
WHR & $0.88 \pm 0.05$ & $0.89 \pm 0.07$ & 0.49 \\
BMI $\left(\mathrm{kg} / \mathrm{m}^{2}\right)$ & $22.32 \pm 3.33$ & $27.70 \pm 5.97$ & $0.0001^{* *}$ \\
\hline
\end{tabular}

Data presented are mean \pm SD; Group 1: Normotensive subjects;

Group 2: Prehypertensive subjects. WC: Waist circumference; HC: Hip Circumference; WHR: Waist-hip ratio; BMI: Body mass index, SD: Standard deviation. $\mathrm{p}<0.05$ is considered to be significant and marked as $*, p<0.001$ is marked as **

Table 2: Basal cardiovascular parameters among the two groups

\begin{tabular}{llll}
\hline Parameters & $\begin{array}{l}\text { Normotensives } \\
(\mathbf{n = 6 6 )}\end{array}$ & $\begin{array}{l}\text { Prehypertensives } \\
(\mathbf{n}=\mathbf{4 0})\end{array}$ & p value \\
\hline SBP (mmHg) & $109.38 \pm 5.88$ & $128.2 \pm 6.50$ & $0.0001^{* *}$ \\
DBP (mmHg) & $66.53 \pm 6.70$ & $75.82 \pm 8.14$ & $0.0001^{* *}$ \\
HR (beats/min) & $76.48 \pm 6.18$ & $89.55 \pm 8.22$ & $0.0001^{* *}$ \\
PP (mmHg) & $42.85 \pm 6.14$ & $52.37 \pm 7.96$ & $0.0001^{* *}$ \\
MAP (mmHg) & $92.03 \pm 8.11$ & $105.68 \pm 10.57$ & $0.0001^{* *}$ \\
\hline
\end{tabular}

Data presented are mean \pm SD; Group 1: Normotensive subjects;

Group 2: Prehypertensive subjects. SBP: Systolic blood pressure, DBP: Diastolic blood pressure, HR: Heart rate, PP: Pulse pressure (SPP-DBP), MAP: Mean arterial pressure (DBP+1/3 PP), SD: Standard deviation. $\mathrm{p}<0.001$ is marked as **

Table 3: Arterial stiffness indices among the two groups

\begin{tabular}{llll}
\hline ??? & $\begin{array}{l}\text { Normotensives } \\
\text { (n=66) }\end{array}$ & $\begin{array}{l}\text { Prehypertensives } \\
(\mathbf{n = 4 0 )}\end{array}$ & p value \\
\hline SI (m/s) & $42.80 \pm 9.52$ & $50.07 \pm 12.96$ & $0.003^{* *}$ \\
RI (\%) & $4.85 \pm 1.58$ & $5.75 \pm 1.30$ & $0.002^{* *}$ \\
\hline
\end{tabular}

Data presented are mean \pm SD; Group 1: Normotensive subjects;

Group 2: Prehypertensive subjects. $\mathrm{p}<0.001$ is considered to be significant $(* *)$.

SI: Stiffness index, RI: Reflection index, SD: Standard deviation 


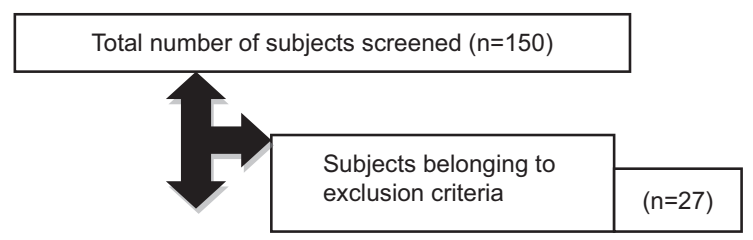

Subjects satisfying inclusion criteria $(n=123)$
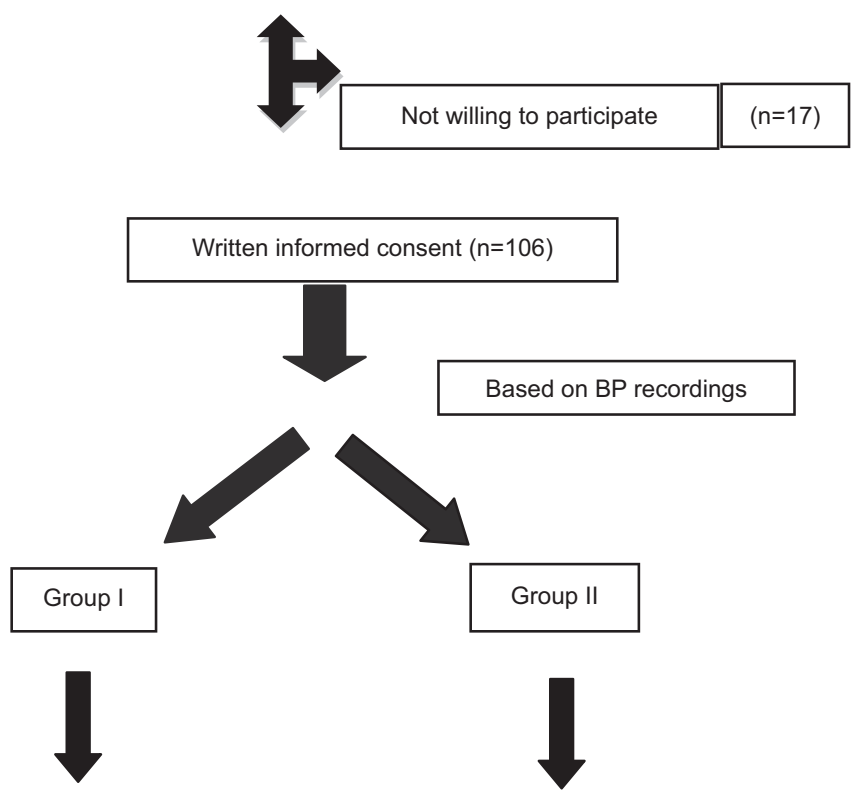

Normotensives $(n=66)$

Prehypertensives $(n=40)$

$\mathrm{BP}(\mathrm{SBP}<120 \mathrm{mmHg}, \mathrm{DBP}<80 \mathrm{mmHg})$

$\mathrm{BP}(\mathrm{SBP} \geq 120-139$ and/or $\mathrm{DBP} \geq 80-89)$

Fig. 1: Participant recruitment and categorization into groups

Table 4: Hematological parameters among the two groups

\begin{tabular}{llll}
\hline & $\begin{array}{l}\text { Normotensives } \\
(\mathbf{n = 6 6 )}\end{array}$ & $\begin{array}{l}\text { Prehypertensives } \\
\mathbf{( n = 4 0 )}\end{array}$ & p value \\
\hline $\begin{array}{l}\text { Hemoglobin } \\
\text { (g \%) }\end{array}$ & $12.03 \pm 2.70$ & $13.98 \pm 2.09$ & $0.0001^{*}$ \\
Hct \% & $36.56 \pm 6.83$ & $41.76 \pm 5.47$ & $0.0001^{*}$ \\
ESR & $7.79 \pm 4.37$ & $5.45 \pm 2.16$ & $0.0001^{*}$ \\
TLC cells $/ \mathrm{mm}^{3}$ & $8381.8 \pm 2043.67$ & $8675 \pm 1839.10$ & $0.04^{*}$ \\
Neutrophil \% & $57.74 \pm 9.53$ & $62.85 \pm 9.51$ & $0.009^{*}$ \\
Eosinophil \% & $3.17 \pm 2.03$ & $3.08 \pm 1.77$ & 0.8 \\
Monocyte \% & $1.52 \pm 0.77$ & $1.88 \pm 0.822$ & $0.02^{*}$ \\
Lymphocyte \% & $34.12 \pm 8.44$ & $38.45 \pm 9.06$ & $0.01^{*}$ \\
NLR & $2.02 \pm 0.94$ & $2.41 \pm 0.90$ & $0.03^{*}$ \\
\hline
\end{tabular}

Data presented are mean \pm SD; Group 1: Normotensive subjects;

Group 2: Prehypertensive subjects. Hct: Hematocrit, ESR: Erythrocyte sedimentation rate, TLC: Total Leukocyte count, NLR: Neutrophil-lymphocyte ratio, SD: Standard deviation. $\mathrm{p}<0.05$ is considered to be significant and marked as *, and $P<0.001$ is marked as **

overall adiposity because of its simplicity and high correlation with percent body fat [16]. BMI could play a key role in the pathogenesis of prehypertension. Earlier studies conducted indicated that higher BMI could be an independent contributing factor for vagal withdrawal and sympathetic overactivity among the prehypertensives $[17,18]$. Furthermore, WC is reported to have a strong association with the development of hypertension [19] and in our study, both WC and HC were significantly increased among the prehypertensives group.

Arterial stiffness indices measured using DVP is represented as two parameters: SI and RI. SI is a measure of large artery stiffness [20], and RI is an accepted measure of vascular tone of small arteries [21]. In our study, both SI and RI reported a significant increase among the prehypertensive group and showed statistically significant positive correlation with BMI and BP. The possible explanation for increased vascular stiffness with increase in BMI may be that the leptin hormone which is known to increase in obesity is reported to cause a reduction in arterial distensibility [22] and extra recruitment of collagen fibers to help "stiffen" large arteries against increased distending pressure [23]. A previous study conducted in 2013 by Malliga et al. indicates that BMI and age are significant determinants of hypertension [24].

NLR is reported to predict the inflammatory status in various cardiovascular pathologies. It is reported that the phagocytic index can be used to predict ischemic heart disease [25]. In this study, NLR is found to be significantly increased among prehypertensives compared to normotensives indicating that inflammation process has been initiated in the precursor stage itself and may be a pathogenic factor in vascular damage [26]. In our study, NLR was not significantly correlated to arterial stiffness indices among the prehypertensives; similar reports are produced by Mehmood et al. [27], while studies conducted by Park et al. have shown quite contrary results [28]. This 
Table 5: Pearson correlation of SI and RI with BMI, BP, HR, and NLR

\begin{tabular}{llllll}
\hline & \multicolumn{2}{l}{$\mathbf{S I}$} & & & $\mathbf{R I}$ \\
\cline { 2 - 3 } \cline { 5 - 6 } & $\mathbf{r}$ & $\mathbf{p}$ & & $\mathbf{r}$ & $\mathbf{p}$ \\
\hline BMI & 0.43 & $0.0001^{* *}$ & & 0.44 & $0.0001^{* *}$ \\
SBP & 0.31 & $0.0001^{* *}$ & & 0.34 & $0.0001^{* *}$ \\
DBP & 0.22 & $0.02^{*}$ & & 0.29 & $0.003^{*}$ \\
PP & 0.2 & $0.04^{*}$ & & 0.16 & 0.1 \\
HR & 0.23 & $0.01^{*}$ & & 0.3 & $0.002^{* *}$ \\
NLR & -0.03 & 0.76 & & 0.08 & 0.37 \\
\hline
\end{tabular}

$\mathrm{p}<0.001$ was considered significant $\left.{ }^{* *}\right)$. SBP: Systolic blood pressure, DBP: Diastolic blood pressure, HR: Heart rate, PP: Pulse pressure, NLR: Neutrophil-lymphocyte ratio, BMI: Body mass index, SI: Stiffness index, RI: Reflection index

may be explained due to the difference in the study design and younger age group of the involved subjects.

\section{Limitations of the study}

This was a cross-sectional study with less sample size. Gender differences in arterial stiffness and NLR could have been evaluated to strengthen the study.

\section{CONCLUSION}

Arterial stiffness indices assessed using DVP could be routinely introduced in clinical practice for identification of high-risk individuals. Gender, BMI, increased arterial stiffness and elevated NLR in prehypertensives could be employed as simple measures to categorize the individuals in the "danger zone" and introduce early lifestyle modifications such as exercise, reduced salt intake, and yoga to improve public health.

\section{REFERENCES}

1. Lim SS, Vos T, Flaxman AD, Danaei G, Shibuya K, Adair-Rohani H, et al. A comparative risk assessment of burden of disease and injury attributable to 67 risk factors and risk factor clusters in 21 regions, 1990-2010: A systematic analysis for the Global Burden of Disease Study 2010. Lancet 2012;380:2224-60.

2. Kearney PM, Whelton M, Reynolds K, Muntner P, Whelton PK, He J. Global burden of hypertension: Analysis of worldwide data. Lancet 2005;365:217-23.

3. Chobanian AV, Bakris GL, Black HR, Cushman WC, Green LA, Izzo Jr JL, et al. The seventh report of the Joint National Committee on prevention, detection, evaluation, and treatment of high blood pressure: The JNC 7 report. JAMA 2003;289:2560-72.

4. Arnett DK, Boland LL, Evans GW, Riley W, Barnes R, Tyroler HA, et al. Hypertension and arterial stiffness: The Atherosclerosis Risk in Communities Study. ARIC Investigators. Am J Hypertens 2000;13:317-23

5. Kaess BM, Rong J, Larson MG, Hamburg NM, Vita JA, Levy D, et al. Aortic stiffness, blood pressure progression, and incident hypertension. JAMA 2012;308:875-81.

6. Liao D, Arnett DK, Tyroler HA, Riley WA, Chambless LE, Szklo M, et al. Arterial stiffness and the development of hypertension. The ARIC study. Hypertension 1999;34:201-6.

7. Gunarathne A, Patel JV, Hughes EA, Lip GY. Measurement of stiffness index by digital volume pulse analysis technique: Clinical utility in cardiovascular disease risk stratification. Am J Hypertens 2008;21:866-72.

8. Sollinger D, Mohaupt MG, Wilhelm A, Uehlinger D, Frey FJ, Eisenberger U. Arterial stiffness assessed by digital volume pulse correlates with comorbidity in patients with ESRD. Am J Kidney Dis 2006;48:456-63.
9. Chatterjee S, Chandra P, Guha G, Kalra V, Chakraborty A, Frankel R, et al. Pre-procedural elevated white blood cell count and neutrophillymphocyte $(\mathrm{n} / \mathrm{l})$ ratio are predictors of ventricular arrhythmias during percutaneous coronary intervention. Cardiovasc Hematol Disord Drug Targets 2011;11:58-60.

10. Akyel A, Yayla C, Erat M, Cimen T, Dogan M, Acikel S, et al. Neutrophil-to-lymphocyte ratio predicts hemodynamic significance of coronary artery stenosis. Anatol J Cardiol 2015;15:1002-7.

11. Aydin M, Yuksel M, Yildiz A, Polat N, Bilik MZ, Akil MA, et al. Association between the neutrophil to lymphocyte ratio and prehypertension. Bratisl Lek Listy 2015;116 suppl 8:475-9.

12. Shah N, Parikh V, Patel N, Patel N, Badheka A, Deshmukh A, et al. Neutrophil lymphocyte ratio significantly improves the Framingham risk score in prediction of coronary heart disease mortality: Insights from the National Health and Nutrition Examination Survey-III. Int J Cardiol 2014;171:390-7.

13. Ferguson TS, Younger NO, Tulloch-Reid MK, Wright MB, Ward EM, Ashley DE, et al. Prevalence of prehypertension and its relationship to risk factors for cardiovascular disease in Jamaica: Analysis from a cross-sectional survey. BMC Cardiovasc Disord 2008;8:20.

14. Mendelsohn ME, Karas RH. The protective effects of estrogen on the cardiovascular system. N Engl J Med 1999;340:1801-11.

15. Yadav S, Boddula R, Genitta G, Bhatia V, Bansal B, Kongara S, et al. Prevalence and risk factors of pre-hypertension and hypertension in an affluent North Indian population. Indian J Med Res 2008;128:712-20.

16. Rodondi N, Locatelli I, Aujesky D, Butler J, Vittinghoff E, Simonsick E, et al. Framingham risk score and alternatives for prediction of coronary heart disease in older adults. PLoS One 2012;7:e34287.

17. Pal GK, Chandrasekaran A, Hariharan AP, Dutta TK, Pal P, Nanda N, et al. Body mass index contributes to sympathovagal imbalance in prehypertensives. BMC Cardiovasc Disord 2012;12:54.

18. Schmid K, Schönlebe J, Drexler H, Mueck-Weymann M. Associations between being overweight, variability in heart rate, and well-being in the young men. Cardiol Young 2010;20:54-9.

19. Pasula S, Kumar SV, Laxmi AN, Adepu K, Ali M. Relationship between waist circumference and body mass index of hypertension in non-teaching staff of government and private schools of Warangal, A.P., India. Int J Curr Pharm Res 2013;3:50-4.

20. Woodman RJ, Watts GF, Kingwell BA, Dart AM. Interpretation of the digital volume pulse: Its relationship with large and small artery compliance. Clin Sci (Lond) 2003;104:283-4.

21. Millasseau SC, Kelly RP, Ritter JM, Chowienczyk PJ. Determination of age-related increases in large artery stiffness by digital pulse contour analysis. Clin Sci (Lond) 2002;103:371-7.

22. Singhal A, Farooqi IS, Cole TJ, O'Rahilly S, Fewtrell M, Kattenhorn M, et al. Influence of leptin on arterial distensibility: A novel link between obesity and cardiovascular disease? Circulation 2002;106:1919-24.

23. Armentano RL, Levenson J, Barra JG, Fischer EI, Breitbart GJ, Pichel RH, et al. Assessment of elastin and collagen contribution to aortic elasticity in conscious dogs. Am J Physiol 1991;260:H1870-7.

24. Malliga E, Alpanaverma, Elangovan I, Bhogireddy N, Bhaskaran AA Gender correlated incidence of hypertension and body mass index in assorted age groups in Dar Es Salaam. Int J Pharm Pharm Sci 2013;5:654-8.

25. Bernhardt V, D'souza JR, Shetty A, Shantaram M, Vaswani R. Evaluation of neutrophil function, opsonising capacity and lymphocyte proliferation for risk of developing ischemic heart disease in Type 2 diabetes mellitus patients. Int J Pharm Pharm Sci 2012;4:318-22.

26. Navarro-González JF, Mora C, Muros M, García J, Donate J, Cazaña V. Relationship between inflammation and microalbuminuria in prehypertension. J Hum Hypertens 2013;27:119-25.

27. Mehmood MJ, Hussain MM, Ahmad SQ. Evaluation of neutrophillymphocyte ratio and arterial stiffness index in middle aged prehypertensive and hypertensive men. J Rawalpindi Med Coll 2014;18 supple 2:171-4.

28. Park BJ, Shim JY, Lee HR, Lee JH, Jung DH, Kim HB, et al. Relationship of neutrophil-lymphocyte ratio with arterial stiffness and coronary calcium score. Clin Chim Acta 2011;412:925-9. 